\title{
A Study of College English Culture Intelligence-Aided Teaching System and Teaching Pattern
}

\author{
Cao Meng-yue ${ }^{1}$, Li Dan $^{2} \&$ Wang Jun ${ }^{3}$ \\ ${ }^{1}$ Yangtze University College of Arts and Sciences, Jingzhou, Hubei, China, 434020 \\ ${ }^{2}$ Hubei Water Resources Research Institute, Wuhan, Hubei, China, 430070 \\ ${ }^{3}$ College of Computer Science, South-Central University for Nationalities, Wuhan, Hubei, China, 430070 \\ Correspondence: Wang Jun, College of Computer Science, South-Central University for Nationalities, 182 \\ Minyuan Road, Hongshan District, Wuhan, Hubei, China
}

Received: January 23, 2020

Accepted: February 22, 2020

Online Published: February 24, 2020

doi: 10.5539/elt.v13n3p77

URL: https://doi.org/10.5539/elt.v13n3p77

\begin{abstract}
College English teaching is supposed to cover both language acquisition and culture learning due to the close relationship between language and culture, taking cultural teaching as an indispensible part of college English courses. With the rapid integration of information technology and English curriculum, artificial intelligence has brought new opportunities to college English teaching, and college English cultural teaching methods are now faced with new innovations. In the age of intelligence, to promote teaching quality and learning effect, artificial intelligence technology can be embedded in English teaching practice, exerting its technical advantages and frontier characteristics. In consideration of integrated developing tendency of college English cultural teaching model and modern information technology, the paper is aimed to design and build up an intelligence-aided system so as to extend the depth and width of the application of modern information technology in college English cultural teaching as well as to exploit the great application potential of modern information technology in college English cultural teaching, thus opening a new way and presenting a direction for college English cultural teaching.
\end{abstract}

Keywords: college English, cultural teaching, artificial intelligence, aid system, teaching model

\section{Introduction}

The paper tends to promote the application of information technology in China's higher education through "Internet + education" smart education model and integrate information technology into cultural teaching, so as to prompt "education informatization" and "cultivation of cultural talents".

\subsection{The Background of Research}

2019 Educational Informationization and Key Points of Network Security Work issued by the General Office of Chinese Ministry of Education clearly stated that it's time to promote the in-depth application of new technologies like big data and artificial intelligence in education and teaching, and to cultivate and improve students' information literacy.

College English education is a part of college humanistic education, and cultural teaching in college English courses is one of the important means to cultivate cross-cultural communication talents. However, there are still some problems in college English culture teaching, such as students' insufficient grasp of cultural knowledge, lacking comparative study between Chinese and English culture, scanty high-quality resources and suitable textbooks, single cultural teaching content and outdated teaching methods, etc. Making full use of modern information technology is an effective way to solve these problems. Modern information network has strong communicability, mobility and interactivity, so its effective use in the cultural teaching can open a new channel for culture teaching, introduce new learning resources, promoting the application of non-traditional education tools based on modern information network technology, which is beneficial to improve students' autonomy and interaction of culture learning.

Therefore, in the age of artificial intelligence, it is necessary to make full use of big data and other modern information technologies to design and establish an intelligent auxiliary system for English culture teaching, and 
to conceive and set up a modern teaching model, so that modern information technology can really contribute to the reform and development of college English culture teaching.

\subsection{Related Works}

In the age of artificial intelligence, big data (Wang, Yang, Liu \& Deen, 2018), edge computing (Wang, Yao, Zheng, Sun \& Song, 2019), cyber-physical system (Tavcar \& Horvath, 2019) and other modern information technologies have developed rapidly, providing a brand new way of learning and an unprecedented new approach for foreign language teaching (Fang, 2019; Xin, 2019).

$\mathrm{Hu}$ Peiran et al. (2018), starting from the definition of education technology, positioned the function of higher education technology center in servicing the whole process of college teaching and learning, and in view of three objects of implementation behavior including technology providers, technology users and technical evaluators, respectively put forward the concrete function orientation, making clear of the role of modern information technology like big data in education in colleges and universities and their status in the development of education reform in the era of artificial intelligence. Smart classrooms based on Internet and Internet of Things technology not only promote the modernization of higher education technology, but also push forward the reform of teaching methods in universities and improve the quality of classroom teaching(Jiang \& He, 2017). The intelligent classroom platform design scheme based on artificial intelligence realized the real-time transmission and distributed storage of control instructions of the classroom platform by utilizing the bottom-level design scheme of remote automatic control and bus integrated control (Chen, 2019). Li \& He (2019) analyzed the effect of intelligent teaching system from the "exercise-feedback" model. Lu Xiaoxia illustrated that the artificial intelligence writing evaluation systems like AWE are now widely used in China college English writing for the purpose of reducing the English Teachers' workload and keeping up with the students' writing level. In her empirical study, the author found that the evaluation system AWE is really beneficial to the students' English writing in spite of some weak points ( $\mathrm{Lu}, 2019)$. Aparicio et al. presented through the experiment that the intelligent information access systems are useful to evaluate the teachers' perceptions regarding the utility of these systems in learning activities. And teachers clearly realized the potential applicability of incorporation of these systems into learning activities in both the preparation and the effective use of these activities in the classroom (Aparicio, 2018). Literatures (Kim, Soyata \& Behnagh, 2018; Jin \& Zhong, 2019; Zhu, Cui \& Liu, 2018) focus on the intelligent learning environment, introduce the practical experience, effectiveness of the smart classroom in higher education as well as the design and application of using models, and discuss the current issues and the future direction of intelligent classroom.

From the above analysis, it can be seen that the existing auxiliary systems relevant to the smart classroom mainly focus on the informatization and digitalization of knowledge, but there are still deficiencies in the initiative, personalization and intelligentization of students' learning (Li \& He, 2019; Pang, Li S., Tang \& Zhong, 2018). In the new era of intelligence, college English should vigorously promote the integration of the latest information technologies such as artificial intelligence and curriculum teaching, and continue to give play to the important role of modern educational technology, especially intelligent information technology, in foreign language teaching (Liu \& Li, 2018; Zhao \& Huang, 2019).

\subsection{The Research Basis}

In 2019, we conducted a questionnaire survey on the application of information technology in college English culture teaching in two colleges. The students who participated in the questionnaire survey covered more than 300 students from the departments of economics, law, foreign language, humanities and media, management, information engineering and other departments of the two colleges. Among the students who participated in the questionnaire survey, 97.6\% had taken the course of College English or English-related courses in their first and second year. This questionnaire covers the students' understanding of the cultural knowledge of English, their interest in cultural differences between Chinese and English, their view on the relationship between English cultural knowledge study and English performance, the way teachers teach cultural knowledge, the application of modern network information technology platforms in College English classes, and its effect in English culture learning, etc..

The survey demonstrated the following results: (1) The application scale of modern information technology in college English culture teaching needs to be expanded. College English classes have already begun to use modern information technology for cultural teaching, but it has not yet formed a certain scale, and the teaching model needs to be further extended and standardized. (2) The effect of modern information technology in cultural teaching is affirmed, but there is still room for progress. The educational function of modern information technology in the teaching of cultural education has won the acceptance to a certain degree, and is 
seen as a tool of modern education, which has a positive effect on the improvement of college English teaching and learning of culture, but the effect of the modern information technology in college English culture teaching still have space for improvement, especially the development of intelligent information technology potential calls for further mining. (3) The application potential of modern information technology in college English culture teaching is huge. Students' grasp of cultural knowledge lags behind their interest and willingness to learn, and the teaching content of college English culture needs to be enriched. The current textbooks cannot fully meet the demands of cultural teaching, and the teaching methods of college English is required to be optimized.

In brief, modern information technology has been utilized in college English classes and its effect has been recognized among students and teachers, but the application of modern information technology in college English culture teaching could be explored in terms of breadth and depth, and the application management needs to be normalized. In the age of intelligence the development of interactive and intelligent English culture teaching auxiliary system is beneficial to complete the above tasks, thus improving the quality and efficiency of English culture teaching.

\section{The System Framework Design}

Intelligent English culture teaching auxiliary system is an intelligent English culture teaching auxiliary platform based on Internet plus, machine learning, deep learning, virtual reality and other intelligent information technologies, which is a powerful supplement and intelligent upgrade to traditional classroom English teaching. The intelligence-aided system consists of five independent and interrelated core layers: acquisition layer, storage layer, security layer, process layer and application layer. The specific framework is shown in Figure 1.

\begin{tabular}{|c|c|c|c|c|}
\hline \multirow{3}{*}{$\begin{array}{c}\text { Application } \\
\text { Layer }\end{array}$} & \multicolumn{4}{|c|}{ E- Intelligent English Culture Teaching Auxiliary System } \\
\hline & APP Platform & WEB Platform & VR Platform & Public Platform \\
\hline & $\begin{array}{l}\text { real-time } \\
\text { service, } \\
\text { interactive } \\
\text { learning }\end{array}$ & $\begin{array}{c}\text { autonomous } \\
\text { management, } \\
\text { personalized } \\
\text { service }\end{array}$ & $\begin{array}{c}\text { data } \\
\text { visualization, } \\
\text { virtual learning }\end{array}$ & $\begin{array}{l}\text { accurate push, } \\
\text { intelligent } \\
\text { services }\end{array}$ \\
\hline $\begin{array}{l}\text { Process } \\
\text { Layer }\end{array}$ & Internet + & ज্ড: $\begin{array}{l}\text { Machine } \\
\text { Learning }\end{array}$ & 88) $\begin{array}{l}\text { Deep } \\
\text { Learning }\end{array}$ & $\begin{array}{ll}\text { Virtual } \\
\text { Reality }\end{array}$ \\
\hline
\end{tabular}

\begin{tabular}{|c|c|c|c|}
\hline \multirow{2}{*}{$\begin{array}{l}\text { Security } \\
\text { Layer }\end{array}$} & $\begin{array}{l}\text { Consensus } \\
\text { Mechanism }\end{array}$ & 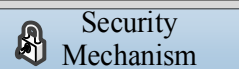 & $\begin{array}{c}\text { Credible } \\
\text { Mechanism }\end{array}$ \\
\hline & $\begin{array}{c}\text { PoW, PoS, DPoS, } \\
\text { BFT et al. }\end{array}$ & $\begin{array}{l}\text { hash, signature, } \\
\text { encryption et al. }\end{array}$ & $\begin{array}{l}\text { TPCM, vTPCM et } \\
\text { al. }\end{array}$ \\
\hline \multirow{2}{*}{$\begin{array}{l}\text { Storage } \\
\text { Layer }\end{array}$} & $\begin{array}{c}\text { Distributed } \\
\text { Database }\end{array}$ & $\begin{array}{c}\text { Distributed File } \\
\text { System }\end{array}$ & $\begin{array}{c}\text { Relational } \\
\text { Database }\end{array}$ \\
\hline & Hbase & HDFS & SQLSever \\
\hline $\begin{array}{l}\text { Acquisition } \\
\text { Layer }\end{array}$ & Data Selection & Cleaning & Data Reduction \\
\hline
\end{tabular}

Figure 1. System Framework

\subsection{Acquisition Layer}

The data acquisition layer is mainly the preprocessing of English cultural data. This layer serves as the basis for the real and virtual visualization of algorithms in the process layer, and the processing results will directly affect the execution effect of the intelligent algorithm. This layer is carried out from the aspects of data selection, data cleaning, data integration, data protocol, etc..

The main purpose of data selection is to select authoritative textbooks, teaching materials and monographs of college English majors as data sources, so as to ensure the authority and accuracy of data, simplify processing steps and improve collection efficiency. Data cleaning mainly refers to the data noise reduction to improve data by single interpolation, multiple interpolations, reverse translation and other methods for the null value, missing, error and exception of some fields in the data. The data protocol is mainly to delete some redundant or less relevant attributes in the attribute set, or to reorganize a variety of related attributes to reduce the size of the data 
set from the spatial level, and finally complete the arrangement and integration of related data of college English culture.

\subsection{Storage Layer}

HBase is a distributed database based on column storage, which can well adapt to mass data and unstructured data storage (Dong, Mou, Cao \& Sun, 2019). SQLSever is a relational database developed and promoted by Microsoft. It has good scalability and can be used across many platforms. Data storage layer, combined with HDFS Hadoop Distributed File System (the Hadoop Distributed File System) (Sun, Sun \& Lin, 2016), makes use of system database which is a hybrid storage mode consisting of distributed database HBASE plus relational database SQLSever, realizes reliable storage and quick query of mass data of college English culture and provides the underlying data support for the upper security control and intelligent processing.

\subsection{Security Layer}

The security layer mainly adopts consensus mechanism, cryptographic mechanism and trust mechanism to realize the secure management and use of system users and data. Consensus mechanism is an important component in block chain technology, which aims to make all honest nodes save consistent block chain view. In this system, technologies such as PoW (Proof of Work) and PoS (Proof of Stake) are used to ensure the security of system users' identity authentication. Cryptographic mechanism is an important means to achieve system security. It ensures the security of data transmission and information exchange in the auxiliary system of English culture teaching through symmetric encryption, asymmetric encryption and other technologies. Based on the Trsuted Platform Control Module (TPCM) and other strategies of China's trusted computing technology, a trusted system operating environment, which is directed at the problem of node credibility of each layer in the system application environment, is built to ensure the trusting relationship between system nodes.

\subsection{Process Layer}

"Internet plus" is a new format of Internet development under innovation 2.0 and a further practical result of Internet thinking plus traditional industries. In process layer of the system, "Internet plus" integrates related English culture resources, and builds intelligent and virtual processing capacity of English cultural learning through the machine learning, deep learning, virtual reality and other modern information technologies, providing application support for upper APP, VR platforms, etc., and offering visual display and intelligent services for accurate real English cultural learning push and interactive learning. The core functions of the process layer include adaptive fuzzy clustering of users in the context of college English culture big data, accurate push of English culture information, personalized learning services based on students' preferences, and virtual reality interactive learning in the context of virtual reality.

\subsection{Application Layer}

The system application layer is responsible for providing the data interface to the service platform to enable the system to use the underlying services. This layer interacts with system users, including four different application platforms like APP platform, WEB platform, VR platform and public platform. Through these platforms, it provides users with learning functions and intelligent services, such as interactive learning, autonomous management, data visualization, virtual learning, accurate push, real-time service and personalized service in order to solve such problems as insufficient cultural teaching in the traditional college English classrooms, lack in comparative study of Chinese and English cultural knowledge, inadequate high-quality education resources and teaching materials, single cultural teaching content, monotonous classroom teaching methods and so forth.

\section{Discussion}

In the age of artificial intelligence, information technology has been changed from a simple tool into the key basic intelligent equipment, providing personalized, virtualized and intelligentized services for college English culture teaching so as to fulfill cultivating the quality of college students in the new era. Ultimately, the application potential of modern information technology in college English culture teaching is demonstrated from the following four aspects, and its teaching mode is worth our thinking.

\subsection{The Change from Universal Learning to Personalized Learning}

Universal learning is a unified collective learning with unified standards and requirements, the same learning content, similar learning mode and teaching methods, which is standard or standardized. Traditional universal learning pays attention to the collective learning of college students, makes college students integrate with the collective group, and cultivates college students' consciousness of group cooperation and collaboration. However, the universal learning ignores the personalized needs of college students, lacks the cultivation and 
guidance of their subjective initiative, and is short of personalized thinking and innovation. In the era of intelligence, we should not only pay attention to the generic learning, but also attach great importance to the differentiated personalized learning in the generic learning. Taking advantage of interactivity, synergy and intelligence of modern information technologies can deepen the college students' existing learning thought, make up for the weak points of current universal learning, and further obtain the useful beneficial enrichment and ascension in the teaching and learning.

\subsection{The Transformation from the Materialized Scene to the Virtual Scene}

Traditional college English cultural teaching is mainly teacher-centered, and classroom teaching is mainly in the form of teaching and learning based on the textbooks with the characteristics of single teaching path, single learning method, and single goal and so on. Combined with the modern information technology of the virtual classroom, students are in the blurred virtual world, completely absorb in the learning atmosphere and learning process created by virtual reality, which is closer to the contemporary college students' new lifestyle. Innovating traditional classroom teaching thinking and integrating various learning data resources can impart college English cultural knowledge to college students more flexibly, more vividly and more completely, and can greatly increase students' learning enthusiasm and initiative, thus promoting the comprehensive qualities of students.

\subsection{The Transition of Informationized Services to Intelligentized Services}

In the times of artificial intelligence, the role and status of information technology in college English culture teaching has been continuously deepened, and the connotation of classroom learning has also undergone important changes. In terms of service concept, it is embodied in the transformation of "informationized service" teaching to "intelligent service" teaching, which corresponds to the intelligent process layer in the framework structure of college English culture teaching auxiliary system. Through the processing of this layer, the transformation from the addition, deletion, modification and search management of traditional data to the intelligent analysis of English culture big data as well as the turn from the physical classroom teaching to the virtual panorama teaching will be completed. Eventually, intelligent information technologies such as machine learning, deep learning and virtual reality will be used to create efficient and intelligent learning environments, and the shift from real informationized services to intelligent services will promote the development of English cultural learning from information into intelligence and competition cross fields.

\subsection{The Conversion from Exam-Oriented Training to Core Literacy Cultivation}

China's Higher Education Law stipulates that "the task of higher education is to train senior specialists with innovative spirit and practicing ability". However, influenced by multiple factors like traditional educational concept and the dilemma between fairness and benefit, etc., exam-oriented education is widespread in higher education. Combined with modern intelligent information technologies, the intelligent service platform of English culture teaching is beneficial to expand the extension of good education resources, deepen the connotation of students' learning resources, solve the dilemma between fairness and benefit and break the dependency on the path of the unified learning standard model. In short, keeping a foothold on the platforms, enlightening wisdom and opening eyes to the whole world, the transformation from exam-oriented training to core literacy cultivation enables students to have the necessary personalities and key abilities to meet the requirements of lifelong development, and promotes their literacy development, wisdom development and all-round development.

\section{Conclusion}

In the intelligent epoch, how to use modern educational tools and resources effectively is the key that we need to consider currently. In this regard, an auxiliary system of intelligent English culture teaching is designed and established, and the future thinking of college English culture teaching is presented and elaborated from the four aspects of personalization, virtualization, intelligentization and quality orientation of cultural learning and teaching. Finally, through the application of relevant auxiliary systems, the denotation of high-class educational resources will be expanded, the connotation of students' learning resources can be deepened, and the unity of knowledge learning and ability cultivation is more likely to be completed.

\section{References}

Aparicio F., Morales-Botello M. L., Rubio M., Hernando A. Muñoz R., López-Fernández H. \& Buenaga M. (2018). Perceptions of the use of intelligent information access systems in university level active learning activities among teachers of biomedical subjects. International Journal of Medical Informatics, 112, 21-23. https://doi.org/10.1016/j.jimedinf.2017.12.016 
Chen F. (2019). Design and implementation of intelligent classroom platform based on artificial intelligence. Modern Electronics Technique, 42(09), 183-186. https://doi.org/10.16652/j.issn.1004-373x.2019.09.043

Dong M. P., Mou S. M., Cao Z. H. \& Sun X. X. (2019). Research and implementation of data storage system for crop diseases and pests based on HBase. Journal of Shandong Agricultural University (Natural Science Edition), 50(02), 264-269. https://doi.org/10.3969/j.issn.1000-2324.2019.02.020

Fang B. (2019). The origin, impact and countermeasures of "Artificial Intelligence Fever" in Chinese $\begin{array}{lllll}\text { universities. } & \text { Modern } & \text { Educational } & \text { 33-39. }\end{array}$ https://doi.org/10.3969/j.issn.1009-8097.2019.04.005

Hu P. R., Li Y. L., Zhou Y. \& Wang Z. X. (2018). The functional orientation of university educational technology center in the age of artificial intelligence_taking the educational technology center of SJTU $\begin{array}{lllll}\text { as an example. } & \text { Modern }\end{array}$ https://doi.org/10.3969/j.issn.1009-8097.2018.11.010

Jiang X. J. \& He Q. (2017). Shanghai Jiao Tong University: Smart classroom boosts teaching innovation. Shanghai Education, 12, 48-48.

Jin Z. Y. \& Zhong L. L. (2019). The "three-in-one" model building and practice exploration of smart classroom-taking Central China Normal University for example. Modern Educational Technology, 29(04), 75-81. https://doi.org/10.3969/j.issn.1009-8097.2019.04.011

Kim Y., Soyata T. \& Behnagh R. F. (2018). Towards emotionally aware AI smart classroom: current issues and directions for engineering and education. IEEE Access, (6):5308-5331 https://doi.org/10.1109/ACCESS.2018.2791861

Li M. F. \& He F. (2019). Analysis on the teaching behaviors of exercise-feedback section in the smart classroom_based on the video analysis of 19 math class presentations in the first prize at provincial $\begin{array}{lllll}\text { level. } & \text { Modern } & \text { Educational }\end{array}$ https://doi.org/10.3969/j.issn.1009-8097.2019.06.009

Liu B. Q. \& Li X. (2018). Research on analysis and application of educational big data based on smart class. Journal of Distance Education, 03, 84-93. https://doi.org/10.15881/j.cnki.cn33-1304/g4.2018.03.009

Lu X. X. (2019). An empirical study on the artificial intelligence writing evaluation system in China CET. Big Data, 7(2), 121-129. https://doi.org/10.1089/big.2018.0151

Pang J. W., Li S., Tang Y. W. \& Zhong S. C. (2018). Study on Chinese reading learning based on wisdom generation in "Internet +" era. E-Education Research, 08, 103-108. https://doi.org/10.13811/j.cnki.eer.2018.08.016

Sun H. X., Sun Z. X. \& Lin T. (2016). Application of data mining technology in fault diagnosis of WindTurbo generator. Journal of South-Central University for Nationalities (Natural Science Edition), 35(04), 81-85. https://doi.org/10.3969/j.issn.1672-4321.2016.04.018

Tavcar J. \& Horvath I. (2019). A review of the principles of designing smart cyber-physical systems for run-time adaptation: Learned lessons and open issues. IEEE Transactions on Systems, Man, and Cybernetics: Systems, 49(1), 145-158. https://doi.org/10.1109/TSMC.2018.2814539

Wang P. F, Yao C, Zheng Z. J., Sun G. Y. \& Song L. Y. (2019). Joint task assignment, transmission and computing resource allocation in multi-layer mobile edge computing systems. IEEE Internet of Things Journal, 6(2), 2872-2884. https://doi.org/10.1109/JIOT.2018.2876198

Wang X., Yang L. T., Liu H. Z. \& Deen M. J. (2018). A big data-as-a-service framework: State-of-the-art and $\begin{array}{lllll}\text { perspectives. } & \text { IEEE Transactions on Big }\end{array}$ https://doi.org/10.1109/TBDATA.2017.2757942

Xin J. Q. (2019). A 10-year review of China's EAP development: Based on a comparison with related studies in international papers. Journal of Pla University of Foreign Languages, 42(03), 64-72.

Zhao B. \& Huang T. Y. (2019). Higher education and its change in the era of artificial intelligence. Shanghai Journal of Translators. Fudan Education Forum, 03, 18-25. https://doi.org/10.13397/j.cnki.fef.2019.04.004

Zhu J. H., Cui H. \& Liu J. W. (2018). Deconstruction and construction: Design and reflection of the smart classroom based on interactive media technology. Research and Exploration in Laboratory, 37(12), 252-256. https://doi.org/10.3969/j.issn.1006-7167.2018.12.059 


\section{Copyrights}

Copyright for this article is retained by the author with first publication rights granted to the journal.

This is an open-access article distributed under the terms and conditions of the Creative Commons Attribution license (http://creativecommons.org/licenses/by/3.0/). 